\title{
A Study of Taiwanese EFL Learners' Syntactic Transfer in Verb Transitivity
}

\author{
Hui-chuan Wang \\ English Department, Wenzao Ursuline College of Languages, Kaohsiung, Taiwan \\ Email: cwfranceswang@gmail.com
}

\begin{abstract}
L1 transfer is generally regarded as an important characteristic of L2 acquisition, also one of the sources of learners' errors. One of the primary transfer between English and Chinese lies in the verb usage since verbs that are transitive in Chinese may be intransitive in English, or vice versa. In the previous studies, the investigation on the syntactic transfer in verb transitivity is only one part of the research focus and not all kinds of verb transitivity are put into analysis. The purpose of the present study is to investigate the nature of syntactic transfer in all kinds of verb transitivity from the interlanguage of Taiwanese EFL college students. The subjects were 56 juniors. The instruments included a demographic questionnaire, a translation test with prompts, and a retrospective report. The demographic questionnaire was used to understand the subjects' personal learning background. The test measured four verb transitivities: complete verb transitivity, incomplete verb transitivity, complete verb intransitivity, and incomplete verb intransitivity. Test takers translated sentences from Chinese into English by using the prompts. When translating, they had to first mark their familiarity with the verb usage in order to explore the extent to which they employed syntactic knowledge or the guessing skills. Finally, each subject wrote a retrospective report to reflect the possible reasons why they made mistakes in the items whose translations resembled Chinese structures. The difficulty and familiarity level of each item and the percentages of using incorrect verb transitivity were calculated and analyzed. The results showed that the extent of syntactic transfer in verb transitivity is not as large as the previous studies. However, both negative and positive transfers were found in the learners' interlanguage. It is interesting to note that for the verbs which the learners were confident with, they were not even aware that they made errors. It seems that familiarity of the meaning of certain verbs made themselves believe that they have acquired the knowledge of the usage and use of the verb transitivity. This study contributed to a growing understanding of the language transfer in verb transitivity.
\end{abstract}

Index Terms - syntactic transfer, verb transitivity, interlanguage, language transfer

\section{INTRODUCTION}

It is assumed that the more similar the languages are, the more likely the first language is to facilitate development in the target language (Kellerman, 1995). There is substantial evidence indicating that the actual distance between the two languages acts as a constraint on transfer (Ellis, 2002). Chinese, the mother tongue of the largest group of English as a foreign language, has been generally perceived as more distant from English and this language distance is one of the sources of learners' errors and difficulties. Although many factors may result in learning difficulties such as developmental sequences and avoidance behavior, language transfer is generally regarded as an important characteristic of L2 acquisition (Odlin, 1989).

Kellerman and Sharwood Smith (1986), Odlin (1989), Kellerman (1995), and James (1998) have redefined Contrastive analysis (CA) and error analysis (EA), which were much discredited during the 1970s and 1980s, and led the field called "Transfer Analysis." Transfer Analysis aims to investigate the discrepancies between the interlanguageTL, which are likely to result from L1 interference (James, 1998). The term 'transfer' or 'interference' has been argued for its close association with behaviorist theories of L2 learning. However, it is now widely accepted that the influence of the learners' native language cannot be explained in terms of habit formation. Sharwood Smith and Kellerman (1986) suggested a theory-neutral superordinate term: crosslinguistic influence, but the term 'transfer' has persisted (Ellis, 2002). Odlin (1989) offers a 'working definition' of transfer as basis for such phenomena: "Transfer is the influence resulting from the similarities and differences between the target language and any other language that has been previously (and perhaps imperfectly) acquired" $(1989$, p. 27). This definition has been far from the original use of the term in behaviorist theories of language learning and provides an adequate basis for the present study.

In traditional accounts of language transfer, the research focus mainly on the errors, which are likely to result in negative transfer. However, three other manifestations of transfer are suggested to consider: facilitation (positive transfer), avoidance (or underproduction), and over-use (Ellis, 2002). In other words, language transfer may be positive or negative depending on the outcome of learning. As for the errors (negative transfer), there has been a substantial amount of empirical works in SLA research conducted in investigating to what extent errors are the result of transfer or are intralingual in nature such as the language development sequence. However, the considerable variance in the proportion of transfer errors was reported by different investigators (Dulay and Burt, 1973; Lott, 1983). 
The learners' L1 can also help L2 learning. Generally, there are two ways to find the facilitative effects. Firstly, Odlin (1989) pointed out that the facilitative effects can only be observed when learners with different native languages are studied and compared. Odlin (1989) believed that facilitation is revealed in a reduced number of errors and in the rate of learning, not in the total absence of certain errors. Secondly, the facilitative effect of the L1 can be adduced by certain types of U-shaped behavior (Kellerman, 1986). Learners may pass through an early stage of development where they have correct use of a TL feature if this feature corresponds to an L1 feature and then replace it with a development L2 feature before finally returning to the correct TL feature. The facilitative effect is evident in the early stages of acquisition. This evidence can be obtained through the longitudinal study of individual learners (Ellis, 2002).

Besides the negative and positive transfer, learners may also avoid using linguistic structures. The effects of the L1 are evidence in what learners do not do instead of what they do (Ellis, 2002). The classic study of avoidance is done by Schachter (1974), who found that Chinese and Japanese learners of L2 English made fewer errors in relative clauses than Persian or Arabic learners because Chinese and Japanese learners produced far fewer clauses. Since the researchers need to look at what learners do not do, it is not an easy job to identify learners' avoidance. Seliger (1989) has addressed that it is only possible to claim that avoidance has taken place when the learner has demonstrated knowledge of form, and when there is evidence that native speakers of the L2 would use the form in the context. Kamimoto, Shimura, and Kellerman (1992) argued that even demonstrating knowledge of a structure is not sufficient and suggested that it is necessary to demonstrate that the structure is not under-used because the equivalent structure is rare in the L1.

The last manifestation of transfer is over-use or 'over-indulgence.' This can occur as a result of intralingual processes such as overgeneralization (Ellis, 2002). For example, Levenston (1979) found that learners may demonstrate a preference for words which can be generalized to a large number of contexts. Over-use can also result from transfer by avoidance or underproduction of some difficult structures and overproduce the other structures. To sum up, the above discussion emphasizes the necessity of considering not only learners' errors, but also such manifestations as facilitation, avoidance, and over-use.

According to Chan (2004), who has conducted a series of studies on learners' language errors, Chinese learners' language transfer has not been the focus of many large-scale studies. In addition to the Yip's work on interlangauge structures of 20 Chinese ESL learners and Chan's (2004) large-scale study on the syntactic transfer from Chinese to English of Hong Kong Chinese ESL learners, there are a number of isolated studies of common ESL errors made by Chinese speakers (e.g., Budge, 1989; Chan, 1991; Jones, 1979; Lay, 1975; Newbrook, 1988; Webster, Ward, \& Craig, 1987; Yip \& Matthews, 1991). In these studies, different phonological, lexical, and structural patterns were investigated and their results all addressed the existence of negative transfer from Chinese to English.

From the research on the differences between Chinese and English by Contrastive analysis (CA) in sentence structures, one of the primary differences lies in the verb usage, and the transitivity patterns of verbs is especially confusing for Chinese learners of English as verbs that are transitive in Chinese may be intransitive in English, or vice versa. Accordingly, many Chinese ESL learners tend to produce errors in this area. Even though much research has devoted to the analysis of errors and interlanguage by Chinese speakers, only a few studies have been reported on the errors in verb transitivity by EFL learners (Chan, 1991; Chan; 2004).

Among these, Chan (1991) and Chan (2004) separately conducted the investigation on verb transitivity. Chan's (2004) large-scale study collected evidence of syntactic transfer from 710 Hong Kong Chinese ESL learners at different proficiency levels by adopting three methodologies: self-reporting in individual interviews, translation (with and without prompts), and grammaticality judgment. One of five error types she collected is the confusion in verb transitivity. How learners used verb transitivity was realized in the translation task. Two high-frequency English intransitive verbs 'care' and 'listen' but different in transitivity patterns in Chinese were chosen. She found half of the participants (48\%) used 'care' as a transitive verb. This misuse of 'care' was more widespread among lowerintermediate students (58\%) than among upper-intermediate students (25\%). Regarding the verb 'listen,' more evidence for syntactic transfer was found. $72 \%$ of total number of participants used the English verb 'listen' as a transitive verb like its Chinese counterpart, $61 \%$ from the upper-intermediate and $77 \%$ from the lower-intermediate group.

Chan's (2004) result showed that many Chinese ESL learners tended to think in Chinese first before they wrote in English based on the individual interviews, and that the surface structures of many of the interlanguage strings produced by the participants were identical or very similar to the usual or normative sentence structures of the learners' first language (L1), Cantonese. Despite the large number of participants and the variety of the tasks, Chan (2004) admitted the limitations on the number of examples collected for each verb transitivity error. Regarding the verb transitivity, only two verbs were used for the investigation of the learners' confusion of verb transitivity and not all kinds of verb transitivity were examined. Consequently, the results from such a small sample of errors may not be representative enough to warrant reliable conclusions. Finally, the interview questions only ask about if learners have a tendency to think in Chinese, but the study did not attempt to understand how learners perceived their errors and explain the reasons for making errors. The extent of the L1 transfer may be limited due to the nature of the tasks.

Chan's (2004) study presents evidence of syntactic transfer in the confusion of verb transitivity based on data obtained from Hong Kong ESL learners. However, the results of Chan's study may not be generated to Taiwan context as Hong Kong learners do not share the same native language and learning background with Taiwanese ESL learners. Hong Kong ESL learners' L1 is Cantonese, while Taiwanese ones' L1 is Mandarin. Even though these two native 
languages share some lexical and structural features, they are generally classified into two languages. Therefore, it can be assumed that the language transfer occurring in Taiwanese ESL learners will be different from Hong Kong learners to some extent. Therefore, to closely look at the syntactic transfer in verb transitivity from the interlanguage of Chinese Taiwanese EFL learners, the aim of this paper only focuses on the transfer in verb transitivity. In total, four types of verb transitivity were examined: complete verb transitivity, incomplete verb transitivity, complete verb intransitivity, and incomplete verb intransitivity. The primary research questions addressed in the present study are as follows:

1. To what extent is the interlanguage produced by Taiwanese college students influenced by their L1Chinese?

2. Are there any similarities or differences in the syntactic transfer in verb transitivity between the upper-intermediate and the lower-intermediate group?

3. Do the learners have a tendency to think in Chinese before writing English sentences?

It is expected that this study may lead to a better understanding of the extent of syntactic transfer in verb transitivity from L1 (Mandarin) to English and help to suggest why it is that Taiwanese EFL learners produced errors in verb transitivity by multiple tasks. The results of this study could be useful to teachers in identifying and understanding students' errors and proposing effective instruction in verb transitivity.

\section{METHODOLOGY}

\section{A. Subjects}

The subjects were 56 junior college students at Applied Foreign Languages Department in central Taiwan. Their average learning length of English was 9.4 years. Out of the 56 students, ten were males and 46 were females. They were divided into two levels based on their performance in a translation test: the upper-intermediate group and the lower-intermediate group. The top 17 students (30\%) were classified as the upper-intermediate, while the bottom 17 students $(30 \%)$ were classified as the lower-intermediate students.

\section{B. Instruments}

The instruments implemented in the study included a translation test with prompts (see Appendix A), a demographic questionnaire (see Appendix B) and a retrospective report (see Appendix C). The translation test was developed by the researcher based on the test objectives of the verb transitivity patterns of English. Test takers were required to translate Chinese sentences into English by making use of the prompts in each item such as the unfamiliar verbs and nouns. As Kamimoto, Shimura, and Kellerman (1992) argued that it is necessary to demonstrate that the structure is not underused, the prompts were provided. These prompts can avoid learners using avoidance strategies and encouraged the test takers to translate all sentences by using their knowledge of syntax and verb transitivity.

When the subjects translated each item, they had to first mark their familiarity of the verb usage to show the extent they employed syntactic knowledge, or on the contrary, the guessing skills. A total of 20 items were randomly distributed in the whole test to measure the following four verb transitivities: (1) complete verb transitivity (5 items); (2) incomplete verb transitivity (5 items); (3) complete verb intransitivity (5 items); and (4) incomplete verb intransitivity (5 items). Since the purpose of the study was to explore the syntactic transfer in only verb transitivity, the scoring was only on the usage of verb transitivity. The total score in the translation test was 20, one point for each item. If one student had correct usage of verb transitivity in an item, he/she got one point or by contrast got zero for incorrect usage of verb transitivity.

The second instrument was a demographic questionnaire to understand the subjects' personal background, including sex, age, and the length of learning English. Two items eliciting the subject's tendency of thinking in Chinese and the frequency of thinking in Chinese were borrowed from Chan's study (2004) which investigated Hong Kong Chinese ESL learners' syntactic transfer. The results from these two questions were expected to show Taiwanese EFL learners' existing tendency in thinking in Chinese when writing in English.

Finally, the subjects completed a retrospective report for the inappropriate translated sentences which resemble Chinese structures. They needed to give explanation for the reasons why they translated literally or utilized Chinese structures. Learners' explanation can account for the extent of the L1 transfer for each type of verb transitivity.

\section{Data Analysis Procedure}

56 tests, questionnaires, questionnaires, and retrospective report were distributed and collected. The descriptive analysis was conducted. The first step was to calculate the descriptive statistics, including the measures of central tendency (mode, median, mean) and dispersion (range and standard deviation). The reliability and validity were calculated and constructed for the quality and fairness of test scores. To further conduct the item analysis of the test, difficulty level and familiarity level were calculated and analyzed. Finally, the percentages of the upper-intermediate and lower-intermediate students using correct verb transitivity in the four types of verb transitivity and the percentages of all the subjects' tendency to think in Chinese by five-point Likert scale were provided for analysis.

\section{RESUltS}


TABLE I shows the descriptive statistics of the test scores. In order to compare every test takers' score with midpoint of the distribution, central tendency were employed: mean, median, and mode. The mean score, the arithmetical average of the translation test, is 10.91. Most testees obtained the scores of 11 and the middle testees gained the score of 11. In other words, averagely, students got half of the test right. According to Heaton (1998), one simple way to measure the spread of marks is to calculate the differences between the highest and lowest scores. In this test, the highest score is 16 and the lowest one is 5. The standard deviation of 2.58 is the degree to deviate from the mean of 10.91 .

TABLE I

DESCRIPTIVE STATISTICS OF TEST SCORES

\begin{tabular}{|l|l|l|l|l|l|l|l|}
\hline \multicolumn{2}{|l|}{ Central Tendency } & Dispersion & $\begin{array}{l}\text { Total } \\
\text { Score }\end{array}$ & Range & Maximum & Minimum & $\begin{array}{l}\text { Standard } \\
\text { Deviation }\end{array}$ \\
\hline Mean & Median & Mode & 20 & 11 & 16 & 5 & 2.58 \\
\hline 10.91 & 11 & 11 & 20 & & 5 \\
\hline
\end{tabular}

\section{A. Reliability}

In order to realize the accuracy, consistency, dependability or fairness of scores, reliability was calculated and analyzed. Since the score for each item was either 1 or 0 , it was appropriate to use Kuder-Richardson Formula 21 to estimate reliability of the whole test. The whole test reliability is .0 .93 , which is at the acceptable level of reliability.

\section{B. Validity}

In addition to reliability, another criterion used to judge the quality of a test is the validity of the test. Validity of a test is the extent to which the test measures what it is supposed to measure. The content validity in the present study was built by constructing a table of specification for the translation test (see TABLE II). The test was designed based on two major categories in the cognitive domain of educational objectives: comprehension and application.

TABLE II

TABLE OF SPECIFICATION FOR THE TRANSLATION TEST

\begin{tabular}{|l|l|l|}
\hline \multirow{2}{*}{ Content } & Objective & Comprehension and Application \\
\cline { 2 - 3 } & Item number & Weights \\
\hline Type A: Complete Transitive Verb & 5 & 5 \\
\hline Type B: Incomplete Transitive Verb & 5 & 5 \\
\hline Type C: Complete Intransitive Verb & 5 & 5 \\
\hline Type D: Incomplete Intransitive Verb & 5 & 5 \\
\hline Total & 20 & 20 \\
\hline
\end{tabular}

\section{Difficulty Level and Familiarity Level}

TABLE III shows the results of the level of difficulty and familiarity of each item. Item facility or item difficulty is an index of how easy an individual item was for the people who take it. The difficulty level of the whole test is from 0.02 to 0.89 . The average difficulty level is 0.54 . According to Oller (1979), items falling between about 0.15 and 0.85 are usually preferred. About $70 \%$ of the items fell in the appropriate difficulty level, including Item 1, 3-7, 9, 11-14, 16, 18, 19 ranging from 0.21 to 0.84 . Only two items seemed too easy for the test takers, Item 2 and 8 , with the same difficulty level of 0.89 , and four items were considered too difficult for testees, Item 10, 15, 17 and 20 from the level of 0.02 to 0.13 .

Familiarity level indicates the degree of familiarity of verb usage expressed by testees. Logically, if the subjects were more familiar with the usage of the verbs, the difficulty and familiarity level would be at least above 0.5. However, even though most testees claimed they were familiar with the verbs of Item 10 and 17, most of them did not give the correct translation, which may be the evidence of the negative transfer from L1. By contrast, only about $20 \%$ of the subjects were familiar with the usage of the verb of Item 18, but almost $80 \%$ of the subjects got the item right. The possible reason may be that the original Chinese structure was similar with the English one. We may assume that there was a positive transfer. However, there may be some other factors which influenced the results; therefore, the results of analysis of the individual items, Item 10, 17 and 18 in TABLE III were discussed.

TABLE III

THE ITEMS WITH DIFFICULTY LEVEL BELOW 0.5

\begin{tabular}{|l|l||l|l|l|l||l|}
\hline Item & 1. & S. & 10. & 15. & 17. & 18. \\
\hline Verb Transitivity type & A & C & D & C & A & C \\
\hline Difficulty & 0.39 & 0.21 & 0.13 & 0.02 & 0.05 & 0.45 \\
\hline Familiarity & 0.29 & 0.21 & 0.80 & 0.14 & 0.52 & 0.84 \\
\hline
\end{tabular}

\section{Percentages of Using Correct Verb Transitivity}


TABLE IV indicates the percentages of the upper-intermediate and lower-intermediate students using correct verb transitivity in the four types of verb transitivity. More than half of the upper-intermediate and half of the lowerintermediate students had correct usage of incomplete verb transitivity, but less than half of the two groups had correct usage of the rest verb transitivities. Compared to the lower-intermediate students, the upper-intermediate outperformed on in four types of verb transitivity. In order to examine if there is significant difference between upper-intermediate and lower-intermediate groups on the mean percentages of correct usage of four types of verb transitivity, a t-test was employed. However, there is no significant difference between these two groups among the four types with the result of t-test of -0.71 .

The percentages help account for the order of the difficulty level in the four types of verb transitivity. As shown in TABLE IV, the order of the difficulty level from the easiest to the most difficult is incomplete verb transitivity, incomplete verb intransitivity, complete verb transitivity and complete verb intransitivity. In other words, both groups have less difficulty in incomplete verb transitivity, but they confronted more difficulty in complete verb intransitivity.

TABLE IV

PERCENTAGES OF USING CORRECT VERB TRANSITIVITY

\begin{tabular}{|l|l|l|}
\hline \multicolumn{1}{|c|}{ Correct usage } & $\begin{array}{l}\text { Upper-intermediate } \\
\mathrm{n}=17\end{array}$ & $\begin{array}{l}\text { Lower-intermediate } \\
\mathrm{n}=17\end{array}$ \\
\hline Test content & $42 \%$ & $37 \%$ \\
\hline Type A: Complete Transitive Verb & $68 \%$ & $50 \%$ \\
\hline Type B: Incomplete Transitive Verb & $25 \%$ & $19 \%$ \\
\hline Type C: Complete Intransitive Verb & $52 \%$ & $48 \%$ \\
\hline Type D: Incomplete Intransitive Verb & \\
\hline
\end{tabular}

\section{E. The Tendency to Think in Chinese}

TABLE V shows the percentages of all the subjects' tendency to think in Chinese by five-point Likert scale. Totally, $89 \%$ of the subjects expressed they had a tendency to think in Chinese before writing English sentences. Almost half of the subjects sometimes think in Chinese, while $27 \%$ of them often and $7 \%$ always think in Chinese.

TABLE V

THE TENDENCY TO THINK IN CHINESE

THE TENDENCY TO THINK IN CHINESE
\begin{tabular}{|l|l|l|}
\hline Frequency & tendency & Number \\
\hline Never & $11 \%$ & 6 \\
\hline Rarely & $5 \%$ & 3 \\
\hline Sometimes & $\mathbf{5 0 \%}$ & $\mathbf{2 8}$ \\
\hline Often & $\mathbf{2 7 \%}$ & $\mathbf{1 5}$ \\
\hline Always & $\mathbf{7 \%}$ & $\mathbf{4}$ \\
\hline Total & $100 \%$ & 56 \\
\hline
\end{tabular}

\section{DISCUSSION AND CONCLUSIONS}

This study aims to find out the evidence of syntactic transfer in verb transitivity from the interlanguage of Taiwanese EFL college learners. The extent of syntactic transfer in verb transitivity, the similarities or differences between upperintermediate and lower-intermediate groups, and the tendency to think in Chinese when writing in English were examined.

The results of the present study show that students seem to have more problems in complete verb intransitivity in terms of the lowest percentages on the correct usage (25\% upper-intermediate vs. $19 \%$ lower-intermediate). The upper-intermediate group outperformed the lower-intermediate group in four types of verb transitivity. Nevertheless, there was no significant difference between upper-intermediate and lower-intermediate groups in the correct usage of four types of verb transitivity. Both groups seemed to perform better on incomplete verb transitivity and incomplete verb intransitivity with the percentages of nearly $50 \%$. The order of the difficulty level from the easiest to the most difficult is incomplete verb transitivity, incomplete verb intransitivity, complete verb transitivity and complete verb intransitivity.

Among 56 subjects, $89 \%$ of them perceived their tendency to think in Chinese before producing English sentences. This result is similar to the findings of Chan's study (2004) of Hong Kong college students. In her study, of the 16 lower-intermediate students, $75 \%$ reported a tendency to think in Chinese. Of the 26 upper-intermediate students, $73 \%$ reported that tendency.

Among the 20 items, only four items provided the evidence of language transfer. Regarding the negative transfer, Item 10 (Type D), 17 (Type A), and 18 (Type C) have low difficulty level (more difficult for most testees) but high familiarity. As for positive transfer, Only Item 4 (Type A) has high difficulty level (easier for most testees) but low familiarity. In other words, the language transfer, either negative or positive, did not frequently occur in learners' interlangauge. This result may be contradictory to the previous studies (e.g., Chan, 2004), which believed learners have a language transfer, especially negative transfer in verb transitivity. In these four items, only incomplete transitive verb (Type B) showed no sign of syntactic transfer, neither positive nor negative. 
In order to examine the possible reasons of the results of low difficulty with high familiarity of the verbs, the analysis of the above items were conducted based on both groups' retrospective reports. To categorize two groups' retrospective reports, five explanations were summarized as follows: (1) They did not know they made errors; (2) They believed they made other kinds of errors; (3) They knew the usage, but forgot how to use it; (4) They were not familiar with the verb, so they translated sentences based on syntactic knowledge; and (5) They translated sentences by using the Chinese structures. The percentages of these five explanations of these two groups were calculated.

\begin{tabular}{|ll|}
\hline Item 10: 我妹妹和他們變(become) 熟(acquaint). & Difficulty level: 0.13 \\
Answer: My younger sister became acquainted with & Familiarity level: 0.80 \\
\hline
\end{tabular}

Errors: become acquaint with them my sister is become acquaint with them $\underline{\text { my sister and they become acquaint }}$

Upper-intermediate: reason (1)-41\%, reason (4)-35\%

Lower-intermediate: reason (1)-41\%, reason (2)-17\%

The first and second sentences were made with correct English structure, but with wrong use of the verb 'become.' It can be easily found that the last one sentence was literally translated with the same word order of Chinese source text. The interesting part of the subjects' retrospective report was that $41 \%$ of the two groups did not know they made mistakes. The second highest percentage for the upper-intermediate group indicated that they admitted their unfamiliarity and tried to rely on their syntactic knowledge of English. By contrast, the lower-intermediate group believed they made other kinds of errors. The learners' retrospective reasons revealed that most of the participants were too confident with their syntactic knowledge, so they were not aware of their errors.

There may be a negative transfer from the source text as the translation looked like the structure of the source text, Chinese. However, none of the participants pointed out they translated sentences by using the Chinese structure. In other words, learners' overconfidence may distract them from identifying their syntactic problem. There is not much difference between two groups' reasons for making mistakes, but the upper-intermediate students seemed to know they could rely on syntactic knowledge when they were not familiar with the usage of the certain verbs. The lowerintermediate, by contrast, were not even aware of the mistakes or believed they made other kinds of errors. We may infer that learners' familiarity of the verbs was limited and may be only on the meanings. Therefore, when translating the familiar verbs, they can not produce correct translation.

\begin{tabular}{|lr|}
\hline Item 17: Tom 試著使自己適應(adapt) 新環境(environment) & Difficulty level: 0.05 \\
Answer: Tom tried to adapt himself to the environment. & Familiarity level: 0.52 \\
\hline
\end{tabular}

Errors: make himself adapt the new environment

let himself adapt the new environment

try to adapt the new environment

Upper-intermediate: reason (1)-47\%, reason (4)-24\%

Lower-intermediate: reason (1)-24\%, reason (2)-24\%, reason (4)-24\%

More than half of the 56 subjects believed they were familiar with the usage of the verb 'adapt,' but the difficulty level fell in nearly zero, which means no one were capable of producing the correct answer. Based on the three sentences produced by the two groups, it seems that none of them knew exactly the usage of the verb 'adapt.' The English words in the sentences were ordered based on the Chinese structures. For example, the first and second sentences use 'make' and 'let' for '使 shi' and 'himself adapt' for '自己適應 zji shi ying' instead of 'adapt himself to.' The testees seemed to use avoidance strategies or alternative ways to translate the third word and skip the Chinese words “自己 zji.” Interestingly, $47 \%$ of the upper-intermediate subjects were unaware that they made errors and $24 \%$ of them acknowledged they were not familiar with the verb after the test. As for the lower-intermediate subjects, $24 \%$ of them thought that they made other kinds of errors. Similar to Item 10, learners' retrospections show that they were too confident with their knowledge of the verb 'adapt' and influenced by the source text. The negative transfer is more obvious than Item 10 as all of the translations had the Chinese structures. It seemed that if learners have very limited knowledge of the usage of a verb's transitivity, they are not aware what errors they made and rely more on their L1. However, none of them expressed that they utilized Chinese structures. We may say that this group of students was not aware that they were under the influence of their L1.

\begin{tabular}{|ll|}
\hline Item 18:這個胸針(brooch)是屬於 (belong)我的。 & Difficulty level: 0.45 \\
Answer: This brooch belongs to me. & Familiarity level: 0.84 \\
\hline
\end{tabular}

Errors: This brooch is belong to me

This brooch $\underline{\text { is }}$ belong to mine

This brooch belong mine

Upper-intermediate: reason (1)-18 \%, reason (3)-35\%, reason (5)-18\%

Lower-intermediate: reason (1)-18\%, reason (3)-35\% 
Both groups indicated that they were familiar with the word 'belong.' As we can see from the first and second sentences, they seemed to know they should put the preposition 'to' after the verb, but they still followed the Chinese structures with 'is' for '是 shi' and 'mine' for ‘我的 wode.' The last sentence consisted of two mistakes. There was no preposition 'to' and they used 'mine' instead 'me.' Both groups (35\%) believed that they knew the usage of 'belong to,' but they forgot how to use it. As many students correctly produced the verb phrase 'belong to,' we may infer that they had the knowledge of this verb usage. However, they were still influenced by the source text and produced two-verb translation. The problem may go to learners' use instead of usage as the knowledge of avoiding putting be-verb with another verb has been taught since junior high school and they have produced the correct verb phrase. When analyzing the learners' retrospection, we can see that $35 \%$ of the two groups admitted that they knew the usage, and they just forgot how to use it correctly. From this response, we may include that learners' capacity of retrieving syntactic knowledge and the use of verb transitivity is one possible factor.

\begin{tabular}{|ll|}
\hline Item 4: 園丁(gardener)正在用軟管澆 hose 花園。 & Difficulty level: 0.79 \\
Answer: The gardener is hosing the garden. & Familiarity level: 0.21 \\
\hline
\end{tabular}

Only $21 \%$ of the subjects stated that they were familiar with the verb usage, but the difficulty level was 0.79 , which indicates the item was quite easy for most of the testees. The possible reason may be that the English sentence structure was similar to the Chinese one and the subjects tried to translate literally. According to Kellerman (1995), learners may sometimes pass through an early stage of development where they manifest correct use of a target-language feature if this feature corresponds to an L1 feature, which can be seen as a positive transfer.

The current study attempted to present the evidence for syntactic transfer from Chinese to English in verb transitivity and found that the extent of syntactic transfer in verb transitivity is not as large as Chan's study. Four items showed the language transfer, including both negative and positive and they account for parts of the transfer as the learners' retrospections have pointed out other factors. First, for the verbs which the learners were confident with, they were not even aware of making errors. We may say that they have not passed the stage of development in verb transitivity, but they may have high familiarity with the meanings of the verbs, which made them believe they have acquired the use of the verbs. Second, the capacity of retrieving acquired knowledge and the use of verb transitivity should be taken into consideration when giving students exercises. Another possible reason may be the influence by the source text (Chinese), so even though they used right verb phrase, but still made ungrammatical sentences. Future work can adopt the form of oral test to present the source text, so the influence from the written source text can be eliminated. Students' syntactic knowledge of verb transitivity can be more explicitly examined.

From the subjects' retrospective reports, we can see that some subjects were neither aware of their errors nor distinguished the kinds of errors they made. To raise learners' awareness of the anomalous structures, some researchers suggested use form-focused instruction, which has a positive effect on the rate of acquisition of a target structure. Chan (2004) also suggested researchers to conduct corpus-based empirical research to establish a comprehensive taxonomy of interlingual errors-both structural and lexical for teachers' reference. The current study contributed to a growing understanding of the language transfer in verb transitivity. The contradictory results provided the evidence that the other factors may have more influences on learners such as the capacity of retrieving acquired knowledge. The familiarity level innovated in the study did provide a clue for the understanding of learners' existing knowledge of verbs. However, it may be limited to the meaning of the verbs. Therefore, in future study, a grammar test of these verbs can be first given for a deep understanding of learners' syntactic knowledge. The learners' explanation in the retrospective report can serve as a basis for designing a questionnaire for revealing learners' reasons for making Chinese-structure English sentences. Difficulty level in the four kinds of verb transitivity between upper-intermediate and lower-intermediate found in the study can lead to a number of pedagogical implications for teachers. While this study has its limitations in population, it would be beneficial to replicate this study on larger and different populations.

\section{APPEndix A Translation TEST With Prompts}

This paper aims to investigate your intuitions about the usage of verbs. Your responses to this paper will be kept strictly confidential and will be used for research purposes only.

\footnotetext{
Translation Task

(1) If you are familiar with the verb in the item, please put a check in the box $\square$ familiar; if not, put a check in the box $\square$ unfamiliar.

e.g., 我們應該關心 care 老人的健康。 familiar $\square$ unfamiliar

(2) Translate the following 20 Chinese sentences into English. You can use the words in parentheses. In some sentences, tense may be used with little or no change in meaning.

e.g., 他打破 (break) 了花瓶 (vase) 。Answer: $\underline{\text { He broke the vase. }}$
} 
1. 不要把你的想法強加 inflict 於我。 $\square$ familiar $\square$ unfamiliar 我覺的 found 這本書蠻容易的。 $\square$ familiar $\square$ unfamiliar 他從事 engage 科學的硏究。 $\square$ familiar $\square$ unfamiliar

4. 園丁 (gardener)正在用軟管澆 hose花園。 $\checkmark$ familiar $\square$ unfamiliar

5. 牛奶聞起來 smell 有酸味了(sour)。 $\square$ familiar $\square$ unfamiliar

6. 班上推選 elect 海倫爲班長(class leader)。

$\square$ familiar $\square$ unfamiliar

7. 他不能讓 make 別人了解他。 $\square$ familiar $\square$ unfamiliar

8. 有些家長認爲 consider 暑假對學生而言是浪費。

$\square$ familiar $\square$ unfamiliar

9. 這痛苦(pain)我無法忍受 bear 。 familiar $\square$ unfamiliar

10. 我妹妹和他們變 become 熟了(acquaint)。 $\circ$ familiar $\square$ unfamiliar

11. 請不要騙 lie 我。 $\square$ familiar $\square$ unfamiliar

12. 這音樂聽起來 sound 是十分悅耳的 (pleasing to the ear)。 $\square$ familiar $\square$ unfamiliar

13. 我準時到達 reach 車站。 $\square$ familiar $\square$ unfamiliar

14. 下週她將 be 一直待在這兒。 $\square$ familiar $\square$ unfamiliar

15. 這女孩對每件事都俊笑 giggle。 $\mathrm{g}$ familiar $\square$ unfamiliar

16. 他們爲嬰孩取名 name 莎莉。口 familiar $\square$ unfamiliar

17. Tom 試著使自己適應 adapt 新環境 (environment)。

$\checkmark$ familiar $\square$ unfamiliar

18. 這個胸針(brooch)是屬於 belong 我的。

$\square$ familiar $\square$ unfamiliar

19. Mary 整個晚上一直 remain 很安靜。 $\square$ familiar $\square$ unfamiliar

20. 善良(Good) 將戰勝 prevail 邪惡(evil)。

$\square$ familiar $\square$ unfamiliar
Answer: Don't inflict your ideas on me.

Answer: I found the book easy.

Answer: He engaged in the study of Science.

Answer: The gardener is hosing the garden.

Answer: The milk smells sour.

Answer: The class elected Helen the class leader.

Answer: He can't make himself understood.

Answer: Some parents consider vacations a waste of time for the students.

Answer: I can't bear the pain.

Answer: My younger sister became acquainted with them.

Answer: Please don't lie to me.

Answer: The music sounds very pleasing to the ear.

Answer: I reached the station on time.

Answer: She will be here all next week.

Answer: The girl giggles at everything.

Answer: They named the baby Sally.

Answer: Tom is trying to adapt himself to the environment.

Answer: This brooch belongs to me.

Answer: Mary remained silent all night.

Answer: Good will prevail over evil.

\section{APPENDIX B DEMOGRAPHIC QUESTIONNAIRE}

1. Gender: $\square$ Male $\square$ Female

2. Age: years old now.

3. How long have you been learning English? years.

4. Do you have a tendency to think in Chinese first before you write English sentences or compositions?

$\square$ Yes $\square$ No

5. If yes, how often do you do this?

$\square$ Never $\square$ Rarely $\square$ Sometimes $\square$ Often $\square$ Always

\section{APPENDIX C RETROSPECTIVE REPORT}

Try to give explanations for the ways you translate the sentences which you did not translate correctly. The explanations can be given in English or Chinese.

Item number: explanation

e.g. For Item 18, I thought the verb [belong] needs an object. I think I used the Chinese structure.

\section{REFERENCES}

[1] Budge, C. (1989). Plural marking in Hong Kong English. Hong Kong Papers in Linguistics and Language Teaching 12, 39-47.

[2] Chan, B. (1991). A study of errors made by F. 6 students in their written English with special reference to structures involving the transitive verb and the passive construction. Institute of Language in Education Journal Special Issue 2, 43-51.

[3] Chan, Y. W. (2004). Syntactic Transfer: Evidence from the Interlanguage of Hong Kong Chinese ESL Learners. The Modern Language Journal 88, 56-74.

[4] Dulay, H. \& Burt M. (1973). Should we teach children syntax? Language Learning 23, 245-258.

[5] Ellis, R. (2002). The study of second language acquisition. Oxford: Oxford University Press.

[6] Heaton, J. B. (1991). Writing English language tests. London: Longman Publishing Company.

[7] James, C. (1998). Errors in language learning and use: Exploring error analysis. London: Longman Publishing Company.

[8] Jones, I. (1979). Some cultural and linguistic considerations affecting the learning of English by Chinese children in Britain. English Language Teaching Journal 34, 55-61.

[9] Kamimoto, T., Shimura, T., \& Kellerman, E. (1992). A second language classic reconsidered-the case of Schachter's avoidance. Second Language Research 8, 231-277.

[10] Kellerman, E., \& Sharwood Smith, M. (Eds.). (1986). Crosslinguistic influence in second language acquisition. New York: Pergamon Press.

[11] Kellerman, E. (1992). Another look at an old classic: Schachter's avoidance. Lecture notes, Tokyo: Temple University Japan. 
[12] Kellerman, E. (1995). Crosslinguistic influence: Transfer to nowhere. Annual Review of Applied Linguistics 15, $125-150$.

[13] Lay, N. D. S. (1975). Chinese language interference in written English. Journal of Basic Writing 1.1, 50-61.

[14] Levenston, E. (1979). Second language lexical acquisition: issues and problems. Interlangauge Studies Bulletin 4, 147-160.

[15] Lott, D. (1983). Analysing and counteracting interference errors. English Language Teaching Journal 37, $256-261$.

[16] Newbrook, M. (1988). Relative clauses, relative pronouns and Hong Kong English. Hong Kong Papers in Linguistics and Language Teaching 11, 25-40.

[17] Odlin, T. (1989). Language transfer: Cross-linguistic influence in language learning. Cambridge: Cambridge University Press.

[18] Oller, J. W. (1979). Language tests at school: A pragmatic approach. London: Longman Publishing Company.

[19] Schachter, J. (1974). An error in error analysis. Language learning 27, 205-214.

[20] Seliger, H. (1989). Semantic transfer constraints in foreign language speakers' reactions to acceptability. In Transfer in Language Production, Hans Dechert and Manfred Raupach (eds.), Norwood, N.J.: Ablex. Cited in Ellis, Rod (1994). The Study of Second Language Acquisition. Oxford: Oxford University Press.

[21] Webster, M. A., Ward, A., \& Craig, K. (1987). Language errors due to the first language interference produced by Hong Kong students of English. Institute of Language in Education Journal 3, 63-81.

[22] Yip, V. (1995). Interlanguage and learnability: From Chinese to English. Amsterdam: John Benjamins Publishing Company.

[23] Yip, V., \& Matthews, S. (1991). Relative complexity: Beyond avoidance. CUHK Papers in Linguistics 3, 112-124.

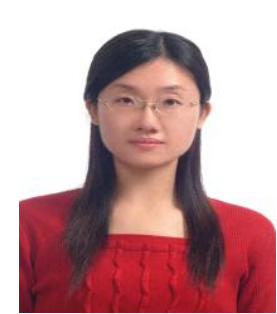

Hui-chuan Wang was born in Taiwan, Jan. $2^{\text {nd }}, 1978$. She got her doctoral degree (TESOL program) in 2010 at Department of English, National Chengchi University (NCCU), Taipei, Taiwan, R. O. C. Her major field is in English teaching and translation pedagogy. Her doctoral dissertation is "Design-based Research on Developing Cooperative Translation Tasks." Before she graduated from NCCU, she worked as a part-time instructor in 7 universities in central Taiwan. Now she is a full-time assistant professor at Department of English, Wenzao Ursuline College of Languages and teaches translation and interpreting. She published one translation learning textbook in Taiwan for college teachers and students “翻easy.com." and has presented more than 10 research articles relating to translation instruction in international conferences held in Taiwan. 